\title{
A Study on College English High-efficiency Class Based on Blended Teaching Mode of Flipped Classroom
}

\author{
Yong Wang \\ School of Foreign Languages, University of Ji'nan, Ji’nan, Shandong, China
}

\begin{abstract}
Under the background of Internet+education, college English, as a compulsory course for non-English majors, urgently needs a new teaching mode and teaching reform. Aiming at the existing problems of college English teaching, new teaching model of college English course based on blended teaching mode of flipped class will expand the depth of high-efficiency classroom, adding difficulties of the class teaching content, improving students' academic challenges, and forcing the students to change from passive learning to active learning, thus to enhance the students' interests in learning, and promote the formation of students' individualized learning methods and the development of students' autonomous learning ability.
\end{abstract}

Index Terms - flipped classroom, blended teaching mode, college English, high-efficiency classroom

\section{INTRODUCTION}

College English teaching is an integral part of higher education. As a compulsory course for non-English majors, college English teaching reform has advanced with the Times and made some achievements in recent years, but the classroom, as the main front of teaching, has not become the focus of the reform, and the teaching effect has not been substantially improved. Under the background of diversified and personalized network digital teaching methods and learning methods, college English teaching and learning urgently need a new teaching model and educational reform (Bi, 2019). How to improve the efficiency of classroom teaching, which is the main link of the teaching reform, how to expand the depth of the curriculum, and how to promote the formation of students' personalized learning methods and independent learning ability has become an urgent problem to be solved.

\section{METHODOLOGY}

\section{A. Concept of Flipped Classroom}

Flipped classroom is the reversed process of transferring knowledge in class and internalizing knowledge after class in traditional teaching. That is to teach knowledge out of the class. Teachers create course videos and let students watch the teaching micro video before the class, who could read the related teaching materials and grasp the importance and difficulty of the course before hand. At the same time teachers provide appropriate exercises to check the students' learning result; then teachers internalize the knowledge, and focus on solving the problems that students fail to master before class (Han, 2018). In the whole reversed process, cooperation and communication between teachers and students, students and students, are created so as to achieve better teaching effect.

\section{B. Concept of Blended Teaching Mode}

Blended teaching mode, which developed from the popularization of information technology, is a new teaching mode which appears in education area. Blended teaching mode was first put forward by Cooney and Laughlin (2000) in the study of preschool children's education. It integrates the advantages of real classroom teaching with the merits of digital or online teaching. Blended teaching mode enables teachers to fully perform their duties to guide, enlighten and monitor the teaching process. It also aims to fully inspire the autonomy, enthusiasm and creativity of students who act as the master of their own study.

Blended teaching mode is an elevation of teaching ideas, which will change students' cognitive styles and teachers' teaching methods and roles (Driscoll, 2002). This kind of change requires not only the change of form, but also the analysis of each student's needs, teaching modules and actual teaching environment, making full use of the complementary advantages of online teaching and classroom teaching to improve students' cognitive effect.

In recent years, with the ongoing promotion of internet and the innovation of education in China, teaching methods based on information technology have been gradually used in college English teaching. Compared with the traditional teaching mode, multimedia teaching in the network environment does bring benefits. College English, as a language learning subject, needs students to show higher autonomy and creativity in the process of learning. Hence, combining online teaching with traditional teaching and designing blended teaching mode in a new way will better meet the needs of college English teaching (Huang, 2006). 


\section{The Connotation of High-efficiency English Classroom}

The so-called high-efficiency class is a kind of teaching mode which is opposite to the low-efficiency and ineffective class. In the process of constructing high-efficiency English class, multiple teaching methods are adopted in strict accordance with the syllabus, and the students become the performers in diverse classroom activities, which fully embodies the essence of education. Teachers actively guide and encourage the students to participate in the independent study and the innovative discussion, and perform the high-quality and high-standard tasks in a certain time. It can be said that through the construction of high-efficiency classroom, it is beneficial to realize the high-level teaching goal of education.

\section{ANALYSIS}

\section{A. Requirements of the Nation and the Society}

The teaching goal in National College English Curriculum requirements (2007) is to cultivate students' comprehensive English application ability and enhance their self-learning ability. The teaching mode should adopt the English teaching mode based on computer and classroom, fully respect the leading role of teachers and the dominant position of students, and promote the formation of students' unique learning methods and the autonomy of students' learning.

The Outline of the Medium and Long Term Development Plan for National Educational Reform (2000-2020) clearly points out that it is necessary to regard education as the fundamental requirement of educational work and view reform and innovation as powerful driving forces for educational development.

In view of the educational reform, the 18th National Congress of the Communist Party of China (CPC) further put forward that quality education should be carried out on all sides, comprehensive reform in the field of education should be deepened, and the quality of education should be raised, and the students should be nurtured to create a new spirit (Chen, 2013).

At the 11th China university teaching forum held in Guangzhou in November 2018, Wu Yan, director of the higher education department of the ministry of education, said that "curriculum is the core element of talent cultivation. The most direct, core and effective thing that students benefit from university is the curriculum"[3].At the same time, Wu Yan put forward the "golden class" standard, which can be summed up as high lever, innovation and challenge.

From the social aspect, at present, the demand for students in the society is to be a all-around talent with practical ability and innovative spirit. However, overemphasizing exams stifles students' creative thinking. If the current teaching mode could not be changed and the crammed lecturing still dominates the class, it will be difficult to cultivate talents who will make great contributions.

From the school aspect, as the follow-up stage of senior high school and the preparatory stage before entering the society, it is of necessity to implement teaching reform. Classroom design and efficiency directly affect students' mastery of knowledge and cultivation of ability, which is an important part of teaching reform.

\section{B. The Deficiency of Current College English Teaching Mode}

Although the college students' English level has had a certain foundation after learning for at least 6 years in schools, it does not mean that the students no longer need to learn English. At present, college English education is mainly classroom-oriented, but because of the differences in students' learning ability and learning methods, the indoctrination-based teaching method is not suitable for every student's learning, and a single teaching process cannot meet the needs of students at different levels. Therefore, contemporary college English teaching needs to update teaching ideas and teaching methods constantly, and change the past infusion teaching mode. It is necessary to gradually change the teacher-oriented classroom mode into a student-centered classroom teaching mode.

English Learning includes listening, speaking, reading, writing and translating. Although the traditional classroom teaching methods are constantly innovating, but listening practice, the most important link in English learning, is not enough, and listening practice in traditional English class is mainly listening to English recordings, watching films and television materials. There is not so many practical materials for listening. Also, the training of speaking mainly focuses on answering the teachers' questions and role-playing in class, and the enthusiasm and total amount of students' participation could not be guaranteed. Reading materials for reading materials are mainly the original texts lacking practical information. Writing and translation practice are mainly some homework left by the teacher, and the exercises after class are far from enough. Therefore, a learning way that can greatly increase classroom efficiency and promote students' autonomous learning after class is urgently needed, in order to make up for the shortcomings in teaching, and to increase the opportunities for students to express themselves and practice after class.

The limitation of traditional teaching mode lies in that the teaching space is too narrow, only limited to the classroom. But the online teaching breaks through the limitation of space, enriches the content of classroom teaching and enhances students' interest in learning. And according to the learning ability of different students, different learning programs after-class can be conducted.

\section{The Benefits of Blended Teaching Mode Used in College English Class}

Blended teaching mode benefits not only students, but also teachers. In the meanwhile, blended teaching mode 
diversifies evaluation methods and makes assessing procedure more rational and fairer.

\section{Benefits to students}

Firstly, Blended teaching mode benefits students. Blended teaching mode can inspire students' autonomy of learning and improve their academic performance. In America, Doctor Canola. Twigg established a Programming Course Redesign to study that whether blended teaching mode is more useful than traditional classroom teaching method. The program got 880 million fund supports from Pew Charitable Trusts and it gave these supports to 30 different schools to adopt blended learning. From 1999 to 2004 the outcome showed that of 30 courses, 25 courses witnessed the significant improvement of students' learning. Besides, they also found out that students could complete more curriculum than ever and they acquired positive learning attitude. This research proved that blended learning reduces the dependence on teachers and arouses autonomy: Students themselves search information online to do their assignments instead of waiting for teachers to tell them everything. It is valuable firstly because they acquire the awareness of autonomous learning and after owning this consciousness, they will learn actively. Students study online to get more information to fully understand the topic that teachers have mentioned. In the process of searching the topic, students think more and have a deeper understanding of the topic. For example, the foreign teacher Robert Cettl in University of Jinan adopts such a blended learning system. When he gives students a certain topic, they search much information online to understand the topic. Then they discuss in groups and compare notes, which can not only help them learn new things but also enhance their awareness of cooperation.

Another example is worth attention: Yan Yan, a student at Central China Normal University, is preparing a class presentation of language teaching and learning principles next week. During the process, not only did he have to prepare for the teaching material in advance, read the online materials uploaded by teachers, but also had to sum up and extracted the essence even rehearsed in the dormitory. Thus students have more independent thinking, which does good to their development.

\section{Benefits to teachers}

Blended teaching mode is good for teachers to find everyone's potential. If students have questions, they can contact teachers online. In the face-to-face classroom there may be fewer chances for students to communicate with teachers, but online communication both can have more interactions. Rather than playing the role of a dominator - as they did in a traditional classroom - teachers can now give their instruction to help all students develop their full potential.

Blended teaching mode improves academic performance and assists teachers in teaching and help teachers improve themselves. Blended instruction is good for teachers to renew the concept of education, diversify teaching methods and eventually become teaching experts. In China, teachers are usually centers of the whole teaching process and students passively receive what teachers says as authorities, which have been existing for a long time. This traditional mode does cause some problems, such as, students lack self-learning awareness and teachers also don't diversify and update their teaching methods.

But blended teaching mode greatly solves these problems. With the help of the blended teaching mode, teachers play roles of being an organizer, conductor and helper. These roles require them to pay attention to each student and take more efforts to improve their teaching.

Teaching philosophy of paying attention to the brand-new guidance of teaching and advocating innovation puts higher requirements for teachers' work. A teacher in Central China Normal University said that the time spent in teaching is two to three times more than that of the previous period, but it is worth it. First of all, the teaching ability is promoted. Secondly, in the situation of attaching great importance to scientific research and ignore teaching in many colleges and universities, the school has its own innovation in the assessment system. The two most obvious changes are the Central China Normal University decides to start an evaluation programme of "teaching-type professors". The first prize is 100,000 yuan, and the first prize course will become the innovation demonstration course of the reform. A number of young teachers grow up and stand out, thus blended teaching benefits teachers as well.

\section{Benefits to teaching assessment}

Furthermore, blended teaching mode diversifies evaluation methods and makes assessing procedure more rational and fairer. Since the reform of school teaching, most of the subject assessment methods have been changed. In the past, the final examination results were given priority to. Now, attendance, class discussions, forum speeches, assignments and quizzes are recorded through the "cloud classroom platform". The teacher could make observation on the whole process. Thus, the new assessment is fairer and more reasonable.

\section{DISCUSSION}

\section{A. Principles of Applying Blended Teaching Mode into College English Class}

First, changing the traditional teaching mode which focused on teaching and adopting a new teaching mode which pays more attention to learning are necessary. One of the biggest characteristics of online teaching is to give full play to the enthusiasm, autonomy and creativity of students, thus teaching can really become student-centered. Teachers can only act as organizers, helpers and promoters throughout the teaching process. According to Ma (2002), as far as college English teaching is concerned, references can be made to the following teaching procedures. This teaching process is divided into four links: (1) In order to facilitate students' self-study, teachers should tell students the teaching progress and class hours of each unit in advance. The learning steps can be used as a reference for students. (2) After learning 
through online courseware or listening to online teaching, they will feed back the difficulties and doubts they encounter to the teacher. (3) After receiving the feedback of students, teachers can go back to the traditional classroom to answer questions and solve questions, and at the same time check the learning effect of students. (4) Students return to the study of network courseware, review what they have learned earlier, and do the relevant exercises and self-test questions assigned on the courseware. Also, the students with higher capacity can start the preview part of the next unit courseware ahead of time.

Secondly, the teaching mode of teacher-centred should be changed. And cooperation between teachers is advocated. Specifically, it means that experienced and influential teachers could be in charge of online teaching, young teachers in charge of classroom teaching. At present, there are lots of foreign language teachers who have profound professional skills and rich teaching experience. However, in traditional classroom teaching, due to time and energy constraints, they can only afford to teach two or three classes, and the number of students in the class is so limited that greatly limits teaching effect of beneficiary students. In the meanwhile, it also caused the loss of teacher resources. While in online teaching, the background knowledge, language points, and text analysis can be made into the relevant network teaching courseware(such as PowerPoint). In this way, not only has the teaching effect been greatly improved, but also, more importantly, the number of beneficiary students has been expanded. It avoids the waste of teacher resources and realizes the sharing of superior resources.

\section{B. Strategies of Blended Teaching Mode Used in English Class}

In order to apply blended teaching mode into practice to improve college English class efficiency, teachers should give students the opportunities to learn independently and some basic requirements should be exploited.

\section{Combining traditional teaching with online teaching}

The main place of college English teaching is still the classroom. In order to improve the teaching efficiency and teaching effect in the classroom, establishing a good relationship between teachers and students seems more crucial and an active learning atmosphere is needed. During the teaching process, the teacher records the problems existing in the students' learning process by summing up the students' learning characteristics. In this way, the formulation of network teaching objectives and plans are more targeted, so as to achieve better teaching effect.

\section{Interacting under multimedia network}

As a language, English needs students to have synchronized vision and audition in the process of learning. The traditional teaching mode can not meet the needs of current learning needs. With the ongoing development of multimedia technology in the network environment, multimedia teaching has been widely used in the process of English teaching, and the teaching effect is obvious. The application of multimedia technology in English teaching can realize the synchronization of students' vision and audition, and improve the efficiency of English teaching to a great extent through the application of teaching courseware. There are two main forms of multimedia technology in network teaching. On the one hand, multimedia demonstration teaching is adopted. The main teaching form is to integrate the teaching content into multimedia courseware, which can steadily reduce the workload of teachers and enhance the teaching effect. The sounds, images and photos used in courseware can help students synchronize vision and audition better. It can effectively help students remember language points. It is superior to the traditional English teaching mode.

On the other hand, online interactive teaching is applied. In the multimedia teaching environment, a large number of information is transmitted to students in the form of images or sounds or words, and the communication between students and teachers is realized at the same time. The teacher arranges the teaching content scientifically by analyzing the result of the students' study. Through the monitoring technology, teachers can know the learning dynamics of students at any time, as a result of cultivating students' autonomous learning ability, and other abilities to analyze and approach problems by themselves.

\section{Adopting three learning styles}

Under blended teaching circumstances, three learning styles are required. First, autonomous learning is required. Language learning is highly demanding for autonomous learning, and the realization of autonomous learning requires students to have independent learning ability and positive learning enthusiasm. Although the teaching under the network media is the simulation of the real teaching occasions, it is also the actual existence of teaching. Through the comprehensive application of sound, image and text, the reading, translation and explanation of the text can be realized, and the online practice and troubleshooting in the classroom can also be realized, thus the students' comprehensive English level can be improved in an all-round way.

Secondly, interactive learning should be implemented. Different from other subjects, the ultimate goal of language learning is to realize the application in life, so the learning of English should realize the communication of language, that is, interactive learning. The teaching under the network environment can realize this characteristic of the language discipline very well.

Thirdly, cooperative learning should be advocated. Cooperation can be realized among students through online learning, such as in some short English conversations, in classroom impromptu language expression. Students do not need to cooperate in groups like traditional classroom teaching. Through the network platform, group cooperation could be achieved and complete the exercise together. Learning in the network environment responds well to the requirements of the new curriculum teaching standards. Students simplify the tedious questions through cooperation. In the process of cooperation, students can experience the fun of learning English, which can improve students' enthusiasm for learning, 
and improve students' cooperative ability, so as to better adapt to the society.

\section{The Concrete Construction of High-efficiency College English Class}

The core content of the efficient classroom teaching reform should take the students' learning as the fundamental starting point to achieve the purpose of building a good classroom teaching soft environment (Liu, 2017). For this reason, classroom teaching consists of four links:

\section{Previewing online and study independently before Class}

Online learning can give full play to students' autonomy in learning. In this link, students become the main body of teaching. Based on this, this model requires students to learn the course content (especially the teaching topic) actively by video watching, data collection, online query, sketch drawing to preview the text and complete guide learning sheet of the teaching content for further study of classroom teaching.

Before each class, the teacher releases the learning task on the network platform, the students work on the pre-class tasks according to the learning content arranged by the teacher, and study the network resources with the question or learn to master some grammar points through quizzes.

\section{Situational exploration and class presentations}

On the basis of students' self-study before class, teachers guide students to conduct self-interpretation and self-exploration of teaching contents by presenting teaching cases (or creating teaching situations). Class presentation is an important part of this model. In class, students should review the learning situation of this section by individuals or groups, and demonstrate and communicate with the whole class. During the process, each student will be a thinker, and a quiet listener. The classroom presentation can be given in the form of written or dubbing works, songs, mind maps, etc., to summarize and show the achievements, opinions, consensus and problems that still need to be discussed in the next class. During this process, students can exercise their cooperative learning ability.

\section{Flipping the Classroom teaching}

Flipping the classroom teaching begins by reviewing the problems that exist in the former class. Teachers mainly teach the important and difficult parts of the course in the classroom, so that the students can quickly master the knowledge of the course. Teachers arouse students' enthusiasm for learning through group discussions, speeches, debates and other classroom activities. They encourage students to give full play to creative thinking to explore problems, and promote students' acquisition of English language. This teaching method has also given full play to the leading role of teachers in the classroom. Before the class is over, both teachers and students should evaluate the reversal effect of the classroom in order to understand the learning effect and promote the classroom teaching.

\section{Feedback and effect evaluation}

After-class feedback is an essential part of the blended teaching mode of college English. In the off-class online learning link, teachers can provide extended resources to assist students in learning further (Wen, 2014).Teachers can communicate with students online and reflect on how to teach better. Moreover, students can also interact and exchange ideas with their classmates to ensure the implementation of students' online learning effect.

The blended teaching mode evaluation includes teachers' self-evaluation, students' self-evaluation, phase evaluation, comprehensive evaluation and so on. Under the blended teaching mode, the diversified evaluation system can play a significant role in promoting the perfection of teaching evaluation system in higher education.

In addition, the construction of the blended teaching mode must have certain conditions: First, teachers should have certain professional knowledge and modern information technology, and can make certain micro-class videos. Secondly, schools should have an online teaching platform, through which students can obtain free learning resources and exchange information with each other.

\section{CONCLUSION}

Blended teaching mode of flipped classroom is a new emerging topic and it is attracting increasing attention from many countries. It is an innovation of teaching method influenced by the development of information technology. The current deficiencies in college English class also require us to update the teaching mode. Now, it should be widely accepted that blended teaching mode will be used in college English class. This paper just makes a skin-deep study of it. More studies of other scholars are expected.

\section{REFERENCES}

[1] Bi, D.R. (2019). Main tasks, emphases, difficulties and breakthroughs of the university classroom revolution. China Higher Education Research, 6: 1-7.

[2] Chen, X.W. (2013). Study on the necessity and feasibility of efficient classroom of college English. Journal of Chinese Education, 2: 80-81.

[3] Cooney, H. \& M. Laughlin. (2000). Blurring the lines of play and work to create blended classroom learning experiences. Early Childhood Education Journal, 3: 165-171.

[4] Driscoll, M. (2002). Blended Learning. E-learning, 3: 26-29.

[5] Department of higher education, Ministry of education. (2007). Teaching requirements for college English courses. Shanghai: Shanghai Foreign Language Education Press. 
[6] Han, Y.F. (2018). Research on the new hybrid college English teaching model based on flipped classroom. Journal of Changchun Normal University, 9:175-180.

[7] Huang, R.H. (2006). Teaching and practice of blended learning. Beijing: Higher Education Press.

[8] Ma, S.X. (2002). Combination of online teaching and traditional classroom teaching: A brief discussion on college Foreign Language teaching reform. Journal of Guangzhou University, 12: 84.

[9] Liu, H.Z. (2017). Application of mixed teaching mode in English classroom teaching. Journal of Jiamusi Vocational College, 2: 372-373.

[10] Wen, Q.F. (2014). Output driven-input driven hypothesis: an attempt to construct a theory of college foreign language classroom teaching. China Foreign Language Education, 2: 3-12.

Yong Wang was born in Jining, China in 1977. He received his Master degree in linguistics from University of Jinan, China in 2012.

$\mathrm{He}$ is currently an associate professor in the School of Foreign Languages, University of Jinan, Jinan, China. His research interests include teaching and intercultural communication. 